\title{
Isolated proteinuria as an initial sign of severe preeclampsia
}

\author{
Takahiro Yamada, Takashi Yamada, Mamoru Morikawa, Masamitsu Takeda, Ryutaro Nishida, \\ Rina Akaishi, Hisanori Minakami
}

Department of Obstetrics, Hokkaido University Graduate School of Medicine, Sapporo, Japan.

Email: taka0197@med.hokudai.ac.jp

Received 21 April 2011; revised 20 May 2011; accepted 27 May 2011.

\begin{abstract}
Two pregnant women who initially developed proteinuria alone followed by serious preeclampsia are presented to emphasize that there is no adequate technical term to express the period of proteinuria alone based on the current criteria of pregnancyinduced hypertension. Case 1 exhibited a urinary protein concentration of $46 \mathrm{mg} / \mathrm{dL}$ in the absence of hypertension, and abdominal pain due to placental abruption with hypertension at gestational week (GW) $29^{-3 / 7}$ and $29^{-4 / 7}$, respectively. Case 2 exhibited a urinary protein/creatinine ratio of 2.67 , developed hypertension, required cesarean section, and developed posterior reversible encephalopathy syndrome at $\mathrm{GW} 28^{-1 / 7}, 29^{-6 / 7}$, and $32^{-0 / 7}$, and on postpartum day 2, respectively. As women with proteinuria alone are not diagnosed as having preeclampsia and as a diagnosis of gestational proteinuria can be made only at 12 weeks postpartum, a prospective technical term applicable to the condition of proteinuria alone is needed to increase physicians' attention to this condition.
\end{abstract}

Keywords: Posterior Reversible Encephalopathy

Syndrome; Proteinuria; Placental Abruption;

Pregnancy-Induced Hypertension

\section{INTRODUCTION}

Based on the current criteria adopted in many countries, women with proteinuria alone are not diagnosed as having preeclampsia until they also exhibit hypertension [1]; in Japan, those who do not develop hypertension are diagnosed as having had gestational proteinuria. Thus, gestational proteinuria is a retrospective diagnosis. These criteria may have been based on the belief that clinical presentation of preeclampsia involves initial hypertension and subsequent proteinuria. However, whether some pregnant women who initially exhibit proteinuria subsequently develop hypertension had not been exten- sively studied. The clinical outcomes of such women with gestational proteinuria, defined as those exhibiting transient proteinuria of $\geq 0.3 \mathrm{~g} /$ day appearing at or after 20 weeks of gestation and disappearing by 12 weeks postpartum, had been believed to be favorable, and proteinuria had been thought not to be an independent predictor of an adverse outcome [2].

However, a recent report indicated that approximately $50 \%$ of women who develop proteinuria $\geq 0.3 \mathrm{~g} /$ day at and after 20 weeks of gestation in the absence of hypertension progress to preeclampsia [3]. If this is the case, it is misleading to suggest that the outcome of pregnancy in patients with isolated proteinuria is favorable.

Here, we present two patients who showed proteinuria initially and subsequently developed hypertension, and finally experienced severe clinical conditions. We emphasize that physicians have no adequate technical term to express the period of proteinuria alone in such patients according to the current criteria of pregnancy-induced hypertension.

\section{PATIENTS AND RESULTS}

This study was approved by the institutional review board of the Hokkaido University Hospital.

Case 1: A 43-year-old nulliparous woman showed blood pressure (BP) of $124 / 75 \mathrm{mmHg}$ and proteinuria (1 + on dipstick) at a regular antenatal visit at gestational week (GW) $28^{-3 / 7}$ in July 2008. She exhibited BP of $119 / 78 \mathrm{mmHg}$, urinary protein concentration of 46 $\mathrm{mg} / \mathrm{dL}$ (Table 1), and weight gain of $1.7 \mathrm{~kg}$ in 1 week, and was diagnosed as having fetal growth restriction (FGR, estimated fetal body weight of $1082 \mathrm{~g}$ ) the following week $\left(\mathrm{GW} \mathrm{29^{-3/7 }}\right.$ ). Blood chemistry revealed anemia only. The patient requested treatment on an outpatient basis despite our recommendation of hospitalization. Thirty-four hours later, the patient presented with abdominal pain, hypertension (BP of $176 / 98 \mathrm{mmHg}$ ), and urinary protein concentration of $120 \mathrm{mg} / \mathrm{dL}$. Placental abruption was suspected based on ultrasonography findings and was confirmed by uneventful emergency cesarean section. A female infant with Apgar scores of 3 
and 7 at 1 and $5 \mathrm{~min}$, respectively, weighing $1086 \mathrm{~g}$ was born. Postpartum course was uneventful in both the mother and neonate. The BP normalized to $121 / 69 \mathrm{mmHg}$ and urinary protein concentration decreased to $<10 \mathrm{mg} / \mathrm{dL}$ on postpartum days 3 and 6 , respectively. Blood tests to screen for anti-phospholipid antibody syndrome were not performed.

Case 2: A 38-year-old woman with a history of two uneventful vaginal deliveries was admitted to hospital due to urinary protein/creatinine ratio (u-PCR) of 2.67 and FGR (estimated fetal body weight, $830 \mathrm{~g}$ ) with BP of $130 / 81 \mathrm{mmHg}$ at GW $28^{-1 / 7}$ in January 2011. She did not have proteinuria before GW 27. BP remained normal until GW 29-6/7, at which time the patient was diagnosed as having preeclampsia because hypertension (158/90 $\mathrm{mmHg}$ ) appeared (Table 1). Although thrombocytopenia of $117 \times 10^{9} / \mathrm{L}$ was seen, her first-trimester platelet count was also relatively low $\left(161 \times 10^{9} / \mathrm{L}\right)$. As u-PCR increased over the gestational period-3.28 at GW $29^{-3 / 7}$ (Table 1), 6.81 at GW 30-6/7 , and 10.78 at GW $31^{-6 / 7}$ with relatively stable BP, ranging from $120 / 70 \mathrm{mmHg}$ to $165 / 90 \mathrm{mmHg}$ - an uneventful cesarean section was performed at GW $32^{-0 / 7}$. A female infant with Apgar scores of 4 and 9 at 1 and 5 min, respectively, weighing $1234 \mathrm{~g}$ was born. The patient complained of contracted visual field on postpartum day 2. Magnetic resonance imaging (MRI) of the brain performed on postpartum days 2 and 9 revealed the presence and disappearance of posterior reversible encephalopathy syndrome, respectively (Figure 1). The visual field was normalized by postpartum day 6. The patient had u-PCR of 6.25 and normal BP $(129 / 81 \mathrm{mmHg})$ on postpartum day 9, and was discharged from hospital on postpartum day 10 . The $\mathrm{u}-\mathrm{PCR}$ decreased to 1.03 on postpartum day 31 . The patient was negative for anti-nuclear antibody, anti-cardiolipin antibody, anti-2GPI antibody, and lupus anticoagulant.

As shown in Table 1, there were no marked differences in any blood test variables between before and after the diagnosis of preeclampsia. Uric acid level was somewhat high in both cases.

\section{DISCUSSION}

Significant proteinuria ( $\geq 0.3 \mathrm{~g} /$ day) preceded the onset of hypertension in the two patients in this study. In addition, these two patients developed serious clinical conditions, i.e., placental abruption and posterior reversible encephalopathy syndrome. Posterior reversible encephalopathy syndrome is a characteristic finding frequently seen in patients with eclampsia [4] and/or visual disturbance irrespective of the presence or absence of pregnancy [5] and represents subcortical edema without infarction [6].

Table 1. Blood pressure, proteinuria, and blood chemistry before and after the diagnosis of preeclampsia.

\begin{tabular}{|c|c|c|c|c|}
\hline & \multicolumn{2}{|c|}{ Case 1} & \multicolumn{2}{|c|}{ Case 2} \\
\hline & $\begin{array}{c}\text { Before } \\
(29-3 / 7 \mathrm{GW})\end{array}$ & $\begin{array}{c}\text { After* } \\
(29-4 / 7 \mathrm{GW})\end{array}$ & $\begin{array}{c}\text { Before } \\
(29-3 / 7 \mathrm{GW})\end{array}$ & $\begin{array}{c}\text { After* } \\
(29-6 / 7 \mathrm{GW}) \\
\end{array}$ \\
\hline Blood pressure $(\mathrm{mmHg})$ & $119 / 78$ & $176 / 98$ & $125 / 79$ & $158 / 90$ \\
\hline Protein in the urine $(\mathrm{mg} / \mathrm{dL})$ & 46 & 120 & 200 & 223 \\
\hline Creatinine in the urine $(\mathrm{mg} / \mathrm{dL})$ & nd & nd & 61 & 56 \\
\hline Hemoglobin $(\mathrm{g} / \mathrm{dL})$ & 7.8 & 8.2 & 11.9 & 11.9 \\
\hline Platelet $\left(\times 10^{9} / \mathrm{L}\right)$ & 336 & 283 & 125 & 117 \\
\hline Total protein $(\mathrm{g} / \mathrm{dL})$ & 5.9 & 5.8 & 4.9 & 4.8 \\
\hline AST (U/L) & 10 & 12 & 24 & 25 \\
\hline LDH (U/L) & 225 & 270 & 223 & 227 \\
\hline Uric acid $(\mathrm{mg} / \mathrm{dL})$ & 6.2 & 6.8 & 5.1 & 5.6 \\
\hline Creatinine $(\mathrm{mg} / \mathrm{dL})$ & 0.7 & 0.7 & 0.56 & 0.54 \\
\hline Fibrinogen $(\mathrm{mg} / \mathrm{dL})$ & 388 & 337 & 330 & 345 \\
\hline D-dimer $(\mu \mathrm{g} / \mathrm{mL})$ & 0.8 & 26.7 & 1.6 & 1.5 \\
\hline Antithrombin activity (\%) & 92 & 84 & 79 & 76 \\
\hline
\end{tabular}

*Just before the performance of cesarean section. nd, not determined; AST, aspartate aminotransferase; LDH, lactate dehydrogenase 

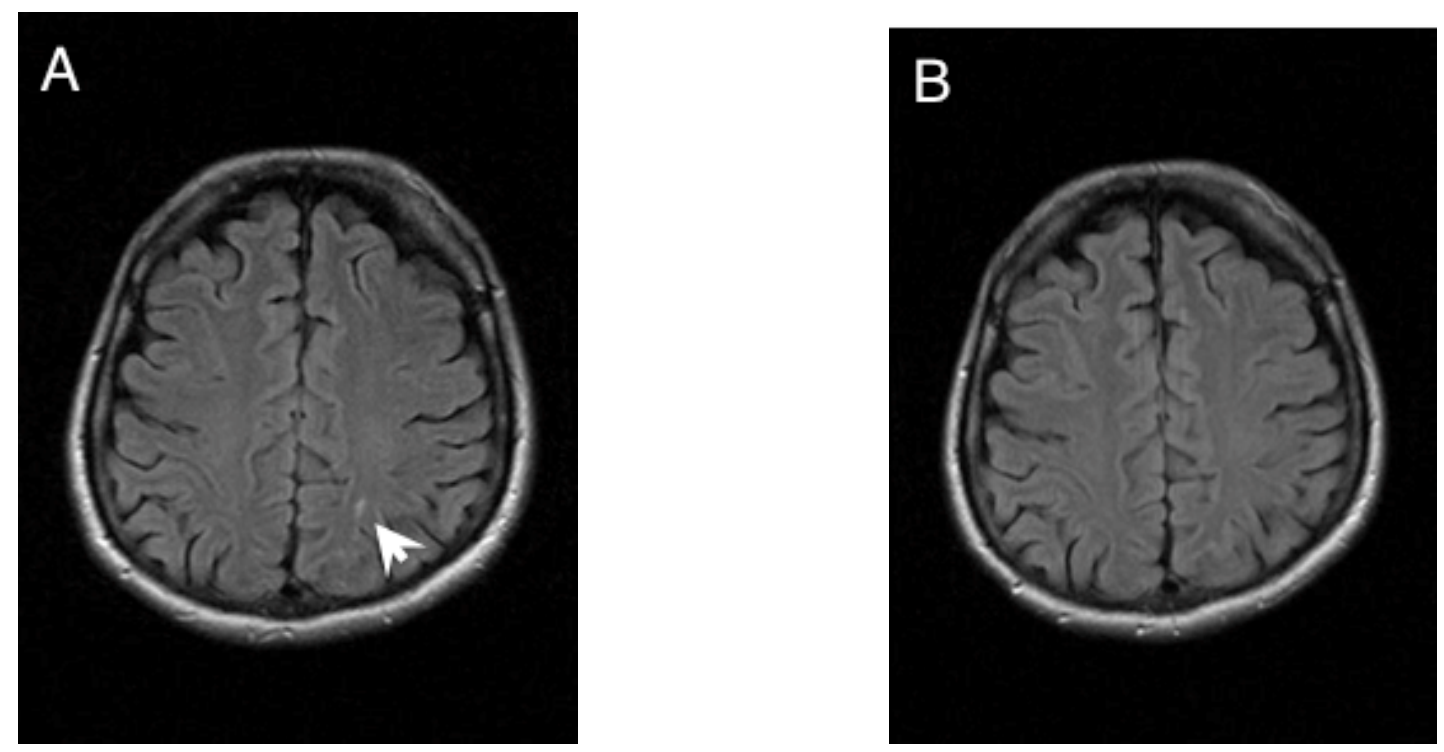

Figure 1. Findings of brain magnetic resonance imaging performed on postpartum days 2 (A) and 9 (B) in Case 2. The arrow indicates a small lesion of posterior reversible encephalopathy syndrome, which disappeared on postpartum day 9 .

Although these two women had a period of pathological proteinuria alone ( 34 hours in Case 1 and 12 days in Case 2), there is no adequate technical term to express the period of proteinuria alone in these patients according to the current criteria [1]. So-called "gestational proteinuria" is applicable only to women who show transient proteinuria ( $\geq 0.3 \mathrm{~g} /$ day) alone between 20 weeks of gestation and 12 weeks postpartum. Thus, the definite diagnosis of gestational proteinuria must wait until 12 weeks postpartum. From the prospective viewpoint, physicians are unable to determine which women with isolated proteinuria (new-onset proteinuria $\geq 0.3 \mathrm{~g} /$ day in the absence of hypertension) will develop hypertension. If pregnancy outcomes of such women with initial proteinuria and subsequent hypertension (which we tentatively call proteinuria-preceding preeclampsia) were similar to those of women with gestational proteinuria, no problems would emerge during or after counseling for women with isolated proteinuria. However, pregnancy outcomes differ markedly between women with gestational proteinuria and proteinuria-preceding preeclampsia [3]. In addition, proteinuria-preceding preeclampsia is relatively common among women with isolated proteinuria [3]. Morikawa et al. reported that 19 $(51 \%)$ of 37 women with isolated proteinuria exhibited additional hypertension and progressed to proteinuriapreceding preeclampsia [3]. These 19 women with proteinuria-preceding preeclampsia gave birth at $<37$ weeks of gestation $(57.9 \%$ vs. $11.1 \%)$ and gave birth to FGR infants $(36.8 \%$ vs. $5.6 \%)$ at a significantly higher rate than the remaining 18 who remained normotensive and were diagnosed as having gestational proteinuria [3]. Meanwhile, the outcomes of women with gestational proteinuria do not differ largely from those of healthy control subjects $[3,7]$. Thus, a significant number of women with isolated proteinuria progress to preeclampsia, and the outcomes of these women are not optimistic, as also suggested in the present study. Therefore, it is misleading to suggest that proteinuria is not independently predictive of adverse outcome [2].

In the UK, $32(10 \%)$ of 325 women with eclampsia in 1992 and $16(7.5 \%)$ of 214 women with eclampsia between February 2005 and February 2006 exhibited proteinuria alone at the time of their last antenatal visit within one week of their first convulsion [8,9]. In a study performed in Japan in 2004, pregnancy-induced hypertension was not diagnosed before the eclamptic fit in 30 of $54(56 \%)$ women with eclampsia [10]. In Sweden, during the period from 1991 to 1992 , the incidence rate of eclampsia (3.3/10,000 pregnancies) increased significantly compared with the incidence $(1.5 / 10,000$ pregnancies) in 1976 to 1980 [11], raising the question of whether the incidence of eclampsia can be reduced by the earlier diagnosis and treatment of hypertension. These reports suggest the need for greater attention in women with proteinuria alone to predict the development of eclampsia and thereby prevent its occurrence.

In conclusion, some women with preeclampsia initially exhibit proteinuria followed by subsequent development of hypertension. Although the outcomes of such women with proteinuria alone are not optimistic, there is no adequate technical term to express the period of pro- 
teinuria alone according to the current criteria of pregnancy-induced hypertension. The occurrence of women who develop eclampsia in the presence of proteinuria alone $[8,9]$, in addition to the two women discussed in this report, indicates the need for a prospective technical term that is applicable to the clinical condition of proteinuria alone to increase physicians' attention to pregnant women with newly developed proteinuria in the absence of hypertension.

\section{REFERENCES}

[1] Report of the National High Blood Pressure Education Program Working Group on High Blood Pressure in Pregnancy. (2000) American Journal of Obstetrics \& Gynecology, 183, S1-22.

[2] Airoldi, J. and Weinstein, L. (2007) Clinical significance of proteinuria in pregnancy. Obstetrical \& Gynecological Survey, 62, 117-124. doi:10.1097/01.ogx.0000253301.55009.ac

[3] Morikawa, M., Yamada, T., Yamada, T., Cho, K., Yamada, H., Sakuragi, N. and Minakami, H. (2008) Pregnancy outcome of women who developed proteinuria in the absence of hypertension after mid-gestation. Journal of Perinatal Medicine, 36, 419-424. doi:10.1515/JPM.2008.062

[4] Thomas, S.V. (1998) Neurological aspects of eclampsia. Journal of the Neurological Sciences, 155, 37-43.

\section{doi:10.1016/S0022-510X(97)00274-8}

[5] Nguyen-Lam, J. and Kiernan, M.C. (2008) Acute cortica blindness due to posterior reversible encephalopathy. Journal of Clinical Neuroscience, 15, 1182-1185. doi:10.1016/i.jocn.2007.04.025

[6] Hinchey, J., Chaves, C., Appignani, B., Breen, J., Pao, L., Wang, A., Pessin, M.S., Lamy, C., Mas, J.-L. and Caplan, L.R. (1996) A reversible leukoencephalopathy syndrome. The New England Journal of Medicine, 334, 494-500. doi:10.1056/NEJM199602223340803

[7] Holston, A.M., Qian, C., Yu, K.F., Epstein, F.H., Karumanchi and S.A., Levine, R.J. (2009) Circulating angiogenic factors in gestational proteinuria without hypertension. American Journal of Obstetrics \& Gynecology, 200, e1-10.

[8] Douglas, K.A. and Redman, C.W.G. (1994) Eclampsia in the United Kingdom. British Medical Journal, 309, 1395-1400.

[9] Knight, M. (2007) Eclampsia in the United Kingdom 2005. British Journal of Obstetrics and Gynecology, 114, 1072-1078.

[10] Minakami, H., Kubo, T., Takeda, S., Kawabata, M., Kobayashi, T. and Nakabayashi, M. (2009) Placental abruption, HELLP syndrome, and Eclampsia in Japan. Nippon Sanka-Fujinka Gakkai Zasshi, 61, 1559-1567.

[11] Kullberg, G., Lindeberg, S. and Hanson, U. (2002) Eclampsia in Sweden. Hypertension in Pregnancy, 21, 1321. doi:10.1081/PRG-120002906 